\title{
Statistical Analysis of Common Diseases among Female College Students of Grade 2-4 in Tianjin Agricultural University
}

\author{
Hongjun Teng ${ }^{1, a}$, Zhenbo Bao ${ }^{2, b^{*}}$ and Fan Yang ${ }^{2, c}$ \\ ${ }^{1}$ Clinic, Tianjin Agricultural University, Tianjin, China, 300384 \\ ${ }^{2}$ Engineering and Technology College, Tianjin Agricultural University, Tianjin, China, 300384 \\ a*hongjun-teng@163.com, bbaozhenbo@sohu.com, 'fanyang20062800@126.com \\ * The Corresponding author
}

Keywords: Female college students; Common diseases; Statistical analysis; Different grades

\begin{abstract}
In order to master the types and distribution characteristics of common diseases among female college students of 2-4 grades in Tianjin Agricultural University, and provide effective basis for health care, the statistical analysis was conducted on the situation of outpatient visits of female college students in grade 2-4 of Tianjin Agricultural University from June 26, 2017 to June 25, 2018. The 9 kinds of common diseases such as colds, upper respiratory tract infection, sprains, fire, skin irritation, bronchitis, conjunctivitis, dysmenorrhea and toothache were analyzed statistically, and it found that the incidence of colds, upper respiratory tract infections are higher. The common diseases of female college students tend to decrease with the growth of grade, among the 550 cases of Tianjin Agricultural University female college students, 272 cases, 152cases, 126 cases are 2, 3 and 4 grade female college students respectively, the proportion of the second, third and fourth grade are 49.5\%, 27.6\% and $22.9 \%$ respectively. The incidence of colds, upper respiratory tract infection, sprains, fire and bronchitis, the second grade was significantly higher than that of the third grade and fourth grade, and the incidence of sprains and conjunctivitis, fourth-grade college students was significantly lower than the second and third grade students. The reasons are that the low grade students have low self-living ability, lack of health care knowledge, and low immune function. The incidence of dysmenorrhea is higher in the third grade students than in second grade and fourth grade, the possible reason is that second-year college students are not easy to see doctors because of their shyness, and the fourth-grade college students are more mature and can solve their own problems, and do not easily see doctors. The incidence of toothache and skin irritation was not significantly related to the female college students in different grades. It is suggested that health care workers should adopt appropriate preventive health care and health education measures to improve the health level of female college students.
\end{abstract}

\section{Introduction}

College students are the important resources of scientific and technological progress and social development, and the backbone of the future national construction [1,2]. The health of college students is the premise and basic guarantee for their successful completion of their studies and healthy growth. At present, the physical healths of college students are affected by various common diseases [3, 4]. To improve the health of college students, it requires the health care workers to take reasonable and feasible measures to actively prevent and treat common diseases in college students. Combined with long-term medical and health care in colleges and universities, from June 26, 2017 to June 25, 2018, the common diseases of female college students in Tianjin Agricultural University were analyzed statistically. The distribution of common diseases of female college students in different grades and the main reasons are analyzed, which can provide information for better preventive health care and health education, promote female students to master the disease prevention and health knowledge, and provide some help for the successful completion of academic and healthy growth of female college students $[5,6]$. 


\section{Statistical Analysis of Female College Students' Common Diseases in Tianjin Agricultural University}

In the outpatient treatment work, from June 26, 2017 to June 25, 2018, statistics were conducted on female college students' common diseases treated by out-patients in Tianjin Agricultural University School Hospital. There were 605 female college students who came to the clinic, the rate of return visits was not within the statistical range, and female college students were between 18 and 25 years old. Female college students have common colds, upper respiratory tract infections (pharyngitis, tonsils, etc.), sprains, fire, skin irritation, bronchitis, conjunctivitis, dysmenorrhea, toothache, eye fatigue, gastroenteritis, stomach pain, hypertension and hypotension, etc. 13 kinds of common diseases. The names, distribution and proportion of female college students' common diseases are shown in Table 1 [7].

Table 1 The distribution and proportion of female college students' common diseases in Tianjin Agricultural University

\begin{tabular}{|c|c|c|c|}
\hline No. & Common diseases & Cases & Proportion[\%] \\
\hline 1 & Colds & 149 & 24.63 \\
\hline 2 & Upper respiratory tract infections (pharyngitis, tonsils, etc.) & 128 & 21.16 \\
\hline 3 & Sprains & 69 & 11.40 \\
\hline 4 & Fire & 43 & 7.11 \\
\hline 5 & Skin irritation & 42 & 6.94 \\
\hline 6 & Bronchitis & 38 & 6.28 \\
\hline 7 & Conjunctivitis & 34 & 5.62 \\
\hline 8 & Dysmenorrhea & 25 & 4.13 \\
\hline 9 & Toothache & 22 & 3.64 \\
\hline 10 & Eye fatigue & 15 & 2.48 \\
\hline 11 & Gastroenteritis & 15 & 2.48 \\
\hline 12 & Stomach pain & 13 & 2.15 \\
\hline 13 & Hypertension and hypotension & 12 & 1.98 \\
\hline Total & & 605 & 100 \\
\hline
\end{tabular}

The 9 kinds of common diseases of female college students with a high proportion of distribution are colds, upper respiratory tract infections (pharyngitis, tonsils, etc.), sprains, fire, skin irritation, bronchitis, conjunctivitis, dysmenorrheal and toothache, and their distribution proportions are shown in Fig 1.

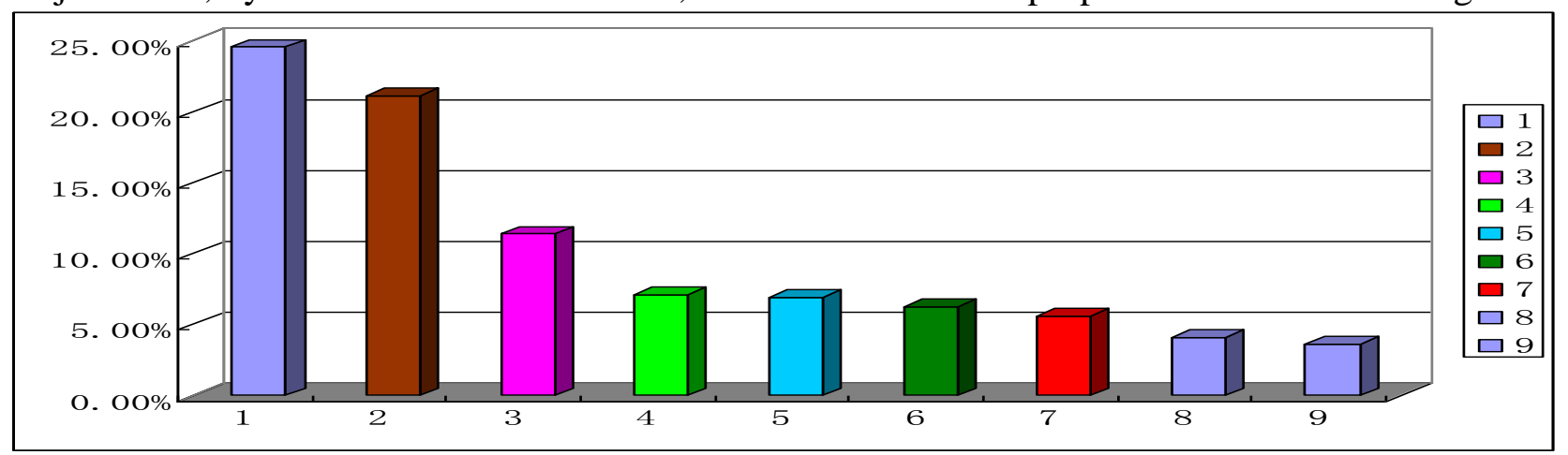

1. Colds 2.Upper respiratory tract infections (pharyngitis, tonsils, etc.) 3. Sprains 4.Fire 5. Skin irritation 6.Bronchitis 7.Conjunctivitis 8.Dysmenorrhea 9.Toothache

Figure 1. The distribution column diagram of female students' common diseases in Tianjin Agricultural University 


\section{Statistical Analysis of Common Diseases of Female College Students in Different Grades in Tianjin Agricultural University}

From June 26, 2017 to June 25, 2018, the distribution patterns of common diseases of female college students in different grades were summarized. The 9 kinds of common diseases of female college students with a high proportion of distribution are colds, upper respiratory tract infections (pharyngitis, tonsils, etc.), sprains, fire, skin irritation, bronchitis, conjunctivitis, dysmenorrheal and toothache, and the specific statistical results are shown in Table 2 [8].

Table 2 The number and proportion of different grade of 9 kinds of common diseases of female college students in in Tianjin Agricultural University

\begin{tabular}{|c|c|c|c|c|c|c|c|c|}
\hline \multirow{3}{*}{$\begin{array}{c}\text { No. } \\
1\end{array}$} & \multirow{3}{*}{$\begin{array}{l}\text { Name } \\
\text { Colds }\end{array}$} & \multirow{3}{*}{$\begin{array}{c}\text { Number } \\
149 \\
\end{array}$} & \multicolumn{6}{|c|}{ Number, proportion of different grade } \\
\hline & & & \multicolumn{2}{|c|}{ Sophomore } & \multicolumn{2}{|c|}{ Junior } & \multicolumn{2}{|c|}{ Senior } \\
\hline & & & 69 & $25.37 \%$ & 40 & $26.32 \%$ & 40 & $31.75 \%$ \\
\hline 2 & $\begin{array}{l}\text { Upper } \\
\text { respiratory tract } \\
\text { infections }\end{array}$ & 128 & 68 & $25 \%$ & 28 & $18.42 \%$ & 32 & $25.4 \%$ \\
\hline 3 & Sprains & 69 & 42 & $15.44 \%$ & 20 & $13.16 \%$ & 7 & $5.56 \%$ \\
\hline 4 & Fire & 43 & 27 & $9.93 \%$ & 6 & $3.95 \%$ & 10 & $7.94 \%$ \\
\hline 5 & Skin irritation & 42 & 16 & $5.88 \%$ & 14 & $9.21 \%$ & 12 & $9.52 \%$ \\
\hline 6 & Bronchitis & 38 & 21 & $7.72 \%$ & 8 & $5.26 \%$ & 9 & $7.14 \%$ \\
\hline 7 & Conjunctivitis & 34 & 13 & $4.78 \%$ & 14 & $9.21 \%$ & 7 & $5.56 \%$ \\
\hline 8 & Dysmenorrhea & 25 & 7 & $2.57 \%$ & 14 & $9.21 \%$ & 4 & $3.17 \%$ \\
\hline 9 & Toothache & 22 & 9 & $3.31 \%$ & 8 & $5.26 \%$ & 5 & $3.97 \%$ \\
\hline & Total & $\begin{array}{c}550 \\
(100 \%)\end{array}$ & $\begin{array}{c}272 \\
(49.5 \% \\
)\end{array}$ & $100 \%$ & $\begin{array}{c}152 \\
(27.6 \%)\end{array}$ & $100 \%$ & $\begin{array}{c}126 \\
(22.9 \% \\
)\end{array}$ & $100 \%$ \\
\hline
\end{tabular}

The second grade female college students have a high incidence of colds, upper respiratory tract infections, sprains, fire, bronchitis, skin irritation and conjunctivitis. Its distribution column diagram is shown in Figure 2.

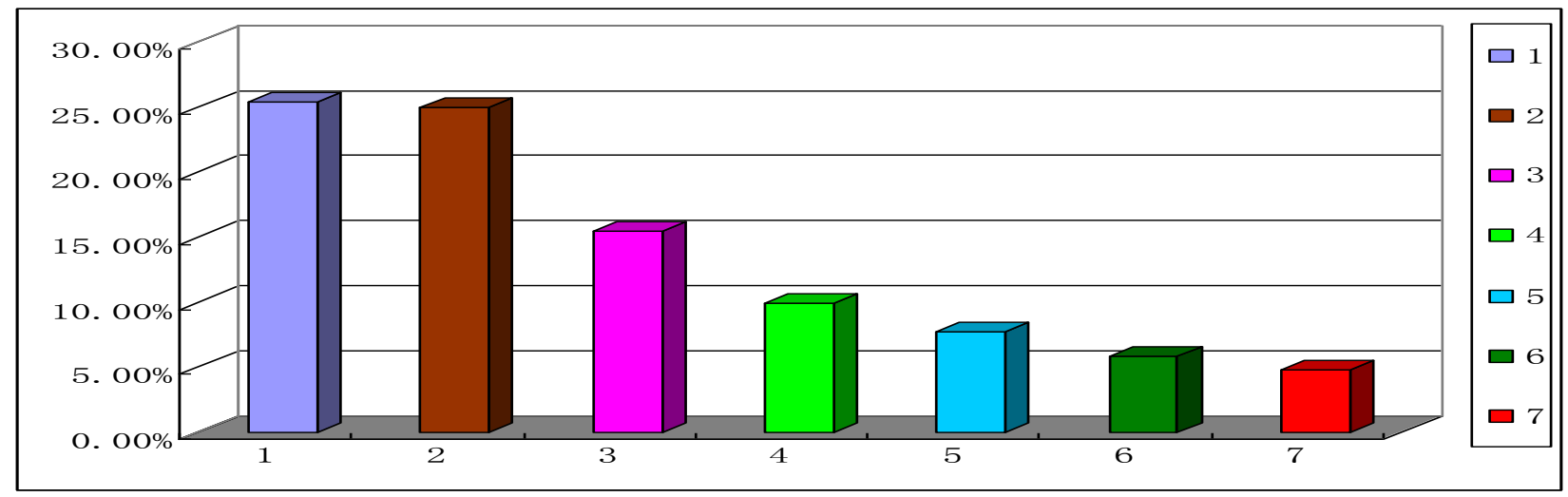

1.Colds 2.Upper respiratory tract infections (pharyngitis, tonsils, etc.) 3.Sprains 4.Fire 5. Bronchitis 6. Skin irritation 7.Conjunctivitis

Figure 2. The distribution column diagram of the second grade female college students' common diseases with a high incidence in Tianjin Agricultural University

The third grade female students have a high incidence of colds, upper respiratory tract infections, sprains, skin irritation, conjunctivitis and dysmenorrhea. Its distribution column diagram is shown in Figure 3. 


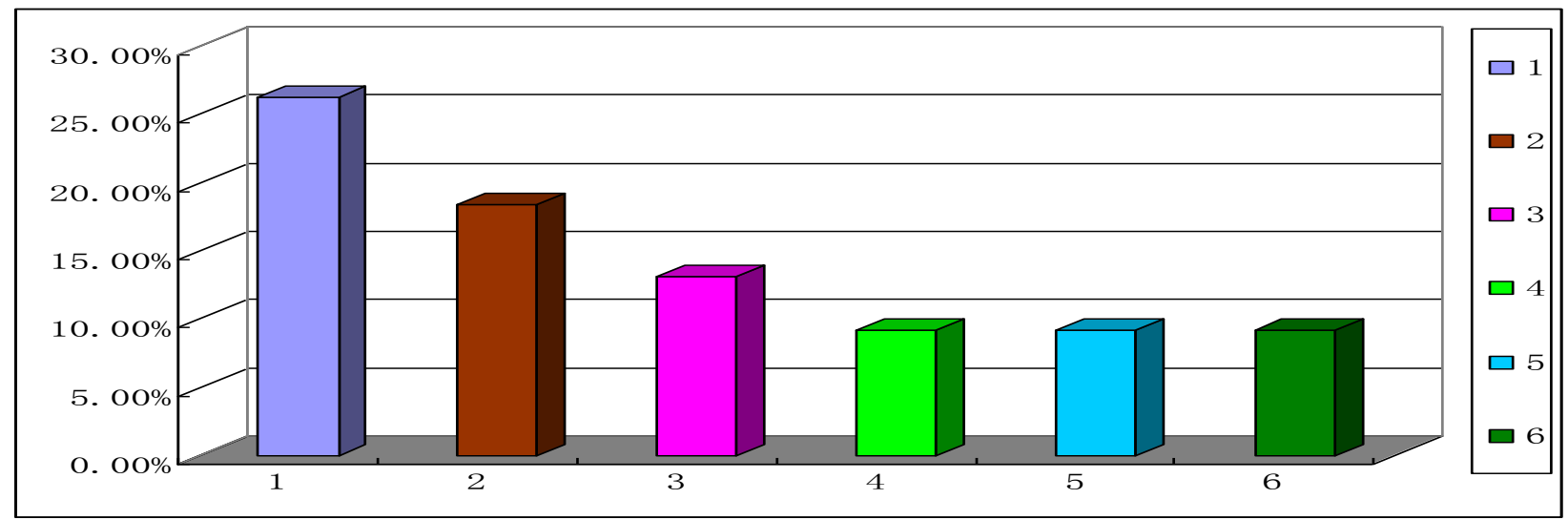

1. Colds 2.Upper respiratory tract infections (pharyngitis, tonsils, etc.) 3. Sprains 4. Skin irritation 5. Conjunctivitis 6. Dysmenorrhea

Figure 3. The distribution column diagram of third grade female college students' common diseases with a high incidence in Tianjin Agricultural University

The fourth grade female college students have a high incidence of colds, upper respiratory tract infections, skin irritation, fire and bronchitis. Its distribution column diagram is shown in Figure 4.

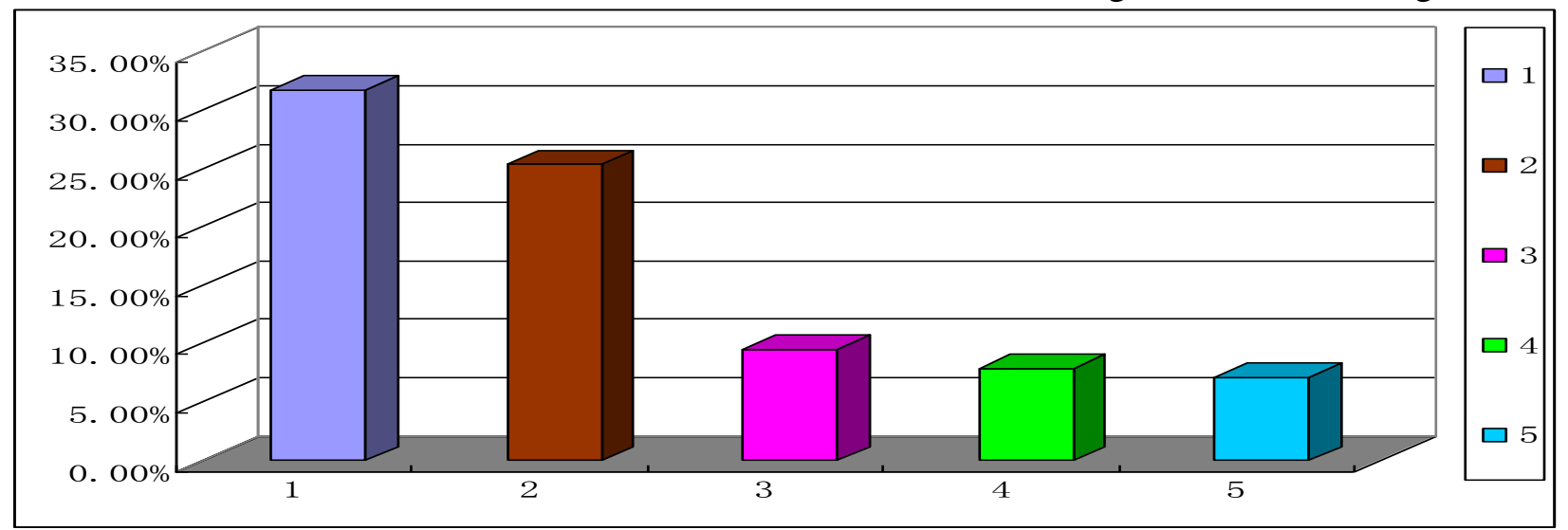

1. Colds 2.Upper respiratory tract infections (pharyngitis, tonsils, etc.) 3. Skin irritation 4. Fire 5. Bronchitis

Figure 4. The distribution column diagram of fourth grade female college students' common diseases with a high incidence in Tianjin Agricultural University

\section{Summary}

Through the statistical analysis of the female college students' common diseases in Tianjin Agricultural University, it found that the 9 kinds of common diseases of female college students with high distribution ratio are colds, upper respiratory tract infections (pharyngitis, tonsils, etc.), sprains, fire, skin irritation, bronchitis, conjunctivitis, dysmenorrheal and toothache, and it found that the incidence of colds and upper respiratory tract infections are higher. The common diseases of female college students tend to decrease with the growth of grade, among the 550 cases of Tianjin Agricultural University female college students, 272 cases, 152cases, 126 cases are 2, 3 and 4 grade female college students respectively, the proportion of the second, third and fourth grade are $49.5 \%, 27.6 \%$ and $22.9 \%$ respectively. The incidence of colds, upper respiratory tract infection, sprain, fire and bronchitis, the second grade was significantly higher than that of the third grade and fourth grade, and the incidence of sprain and conjunctivitis, the fourth grade college students was significantly lower than the second and third grade students. The reasons are that the low grade students have low self-living ability, lack of 
health care knowledge, and low immune function. The incidence of dysmenorrhea is higher in the third grade students than in second grade and fourth grade, the possible reason is that second grade college students are not easy to see doctors because of their shyness, and the fourth grade college students are more mature and can solve their own problems, and do not easily see doctors. The incidence of toothache and skin irritation was not significantly related to the female college students in different grades.

\section{Acknowledgements}

This work was financially supported by the Project of Tianjin Agricultural University Education and Teaching Reform Research (2016-A-04).

\section{References}

[1] P.H. Wang: Journal of Anhui Institute of Education, Vol. 25 (2007) No.6, p.89-92.

[2] Q.B. Wang, X. Shi, Y.Y. Wei: China Medical Herald, Vol. 6 (2009) No.26, p.120.

[3] X.C. Sun: China Medical Engineering, Vol. 19 (2011) No.12, p.149-150.

[4] W.J. Liu: Journal of Guangdong University of Petrochemical Technology, Vol. 23 (2013) No.5, p.35-37.

[5] Z,H, Lu: Journal of Qiqihar University of Medical, Vol. 36 (2015) No.11, p.1664-1665.

[6] Y.H. Feng, M.Y. Wu, H.L. Chen: Journal Traditional Medicine Management, Vol. 24 (2016) No.10, p.167-169.

[7] S.F. Wang, L.Z. Xu and J. Fang: Chin J Sch Health, Vol. 28 (2007) No.7, p.609-610.

[8] Q.T. Wu, J.W. Gan: Health Medicine Research and Practice, Vol. 12 (2015) No.5, p.86-88. 